\title{
CURATING A FUTURE EARTH
}

\section{LEE BEAVINGTON}

Simon Fraser University

Kwantlen Polytechnic University

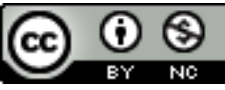

\begin{abstract}
In fall 2019, I enrolled in SFU's President's Dream Colloquium course, Creative Ecologies: Reimagining the World. One of the scholars we read was anthropology professor Dr. Shannon Mattern. My creative response to Mattern's paper-"The Big Data of Ice, Rocks, Soils, and Sediments"- offered an alternative way to engage with her scholarship. In searching for poetic and concise turns of phrase, I noted how her word choice and image-making related to her essay's construction. I sought out bits of data from her paper, re-arranged them into a cohesive unit, and from this garnered a deeper meaning of her intent and expertise. I also noted what was absent or lacking, and this deficit of words, specifically toward should we be exploiting the planet for research?' inspired me to emphasize this in my found poem.
\end{abstract}

Keywords: poetic inquiry, creative ecologies, climate science, Shannon Mattern, climate crisis 


\section{Curating a Future Earth*}

muddy icy soggy

library of the earth

matter out of place

saturated with ironies

layers of abstraction

mud and rocks on a shelf

lakes that have evaporated

icebergs that no longer exist

arks of the apocalypse

await digitization

ASCII text

$$
\begin{aligned}
& \text { floppy disks } \\
& \text { phosphates } \\
& \text { precipitation } \\
& \text { phytoplankton } \\
& \text { fertilizers } \\
& \text { non-relational flat-file } \\
& \text { graceful degradation } \\
& \text { suspended life } \\
& \text { entangled in } \\
& \text { terrestrial transformation } \\
& \text { stalactites } \\
& \text { stalagmites } \\
& \text { particulates }
\end{aligned}
$$

follow epistemological protocols

questions no one ever thought to ask

boreholes

ice cores

pollen spores

megafonds

freezer farms 
what do the rocks say?

over and over again

window to the Earth's past

dirtier the deeper you go

the old ontological question

what is alive?

dredged petroleum contamination

building becomes the end in itself

the unbearable becomes inevitable

leaky boats

ride the rising waves

*All phrases and words taken from Shannon Mattern, "The Big Data of Ice, Rocks, Soils, and Sediments," Places Journal, November 2017. Accessed 22 Oct 2019.

https://doi.org/10.22269/171107 